\title{
In memoriam Charles-André Richon
}

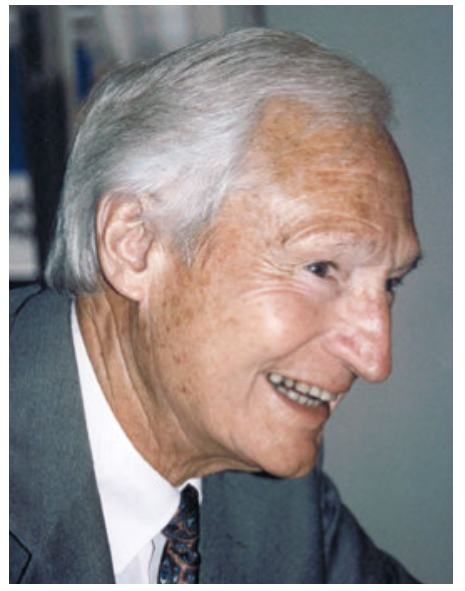

Charles-André Richon (1929-2017)

Dr Ch.-A. Richon a étudié la médecine à Lausanne. Après sa formation de chirurgien, il a travaillé pendant plusieurs années à la Chaux-de-Fonds. A la fin des années 1960, il est revenu en Valais et a été nommé à la tête du service de chirurgie de l'hôpital de Sion. Il s'est pleinement engagé dans la planification et la réalisation du nouvel Hôpital de Champsec dont il a été l'un des derniers chirurgiens généralistes.

De 1985 à 1987 le Dr Richon a présidé la Société de Traumatologie et de Médecine des Assurances dont il était membre d'honneur.

Le Patron a été président du collège des chefs de service. Il a toujours forcé le respect de ses collègues des différents départements de l'hôpital. C'était avant tout un médecin qui gagnait immédiatement la confiance de ses patients. Dr Richon a transmis à des générations

\section{Pour ceux qui le connaissaient personnelle-} ment, "Coulou» était un amuseur, un véritable troubadour, connaissant par cœur le répertoire de la chanson française.

d'assistants ses connaissances médico-chirurgicales. Il a également transmis l'éthique qu'il avait héritée de ses Maîtres lausannois, en particulier le Prof. Pierre Decker qu'il citait volontiers: «La plus grande fierté d'un chirurgien, c'est de guérir son Patient sans devoir l'opérer». Dr Richon était aussi un meneur d'hommes qui avait beaucoup de considération pour ses collaborateurs, grands ou petits. Un jour par exemple, il avait invité ses assistants du service de chirurgie à une journée inoubliable de ski à Chamonix, les guidant entre les crevasses le long de la Vallée Blanche.
Habituellement le soir, après sa journée de consultations et le tour dans son service, il passait dans le bureau des internes pour prendre connaissance des problèmes et des admissions du jour. Les lundis soir, une fois les questions médicales réglées, ses assistants arrivaient à orienter la conversation sur ses activités du week-end précédent et le Patron racontait, avec passion mais modestie, ses courses en haute montagne accompagné de son guide avec qui il faisait le Weisshorn, la traversée du Zinalrothorn, le Cervin et beaucoup d'autres. En parallèle à son activité médicale, le Colonel Richon a mené une carrière militaire de milice, couronnée par le commandement du Régiment d'Infanterie Montagne 6, le Régiment Valaisan, dont il était très fier. Les années passèrent; à 60 ans, il s'est remarié avec Eliane Escher puis a profité d'une retraite bien méritée. Il est toujours resté un montagnard authentique, grimpant sur les sentiers vers les cabanes du Club Alpin Suisse, lui devant, avec son sac à dos. Sa femme l'accompagnait avec le chronomètre en main pour être sûre que la forme physique soit toujours au rendez-vous. A l'opposé, dès que le Joran se levait sur le lac Léman, ils embarquaient sur leur dériveur, un 4.7, et allaient tirer des bords au large du château de Chillon, lui derrière, à la barre.

Pour ceux qui le connaissaient personnellement, "Coulou» était un amuseur, un véritable troubadour, connaissant par cœur le répertoire de la chanson française, imitant Georges Brassens et sa Margot qui dégrafait son corsage.

Il avait suivi le collège à Sion et avait été baigné de culture grecque et latine. 50 ans après sa maturité, il était capable de réciter, en grec, des vers des tragédies de Sophocle et en latin les discours de Cicéron qui haranguait les sénateurs romains.

Le Dr Richon était un polyglotte autodidacte, il parlait l'anglais, l'allemand, l'italien et même le russe. Il a appris le patois valaisan lors de ses cours de service militaire et avec ses amis rotariens ainsi que le «Zermattertitsch» qu'il parlait comme un indigène du coin grâce à ses fréquents séjours au pied du Cervin.

Sa santé s'est brusquement détériorée à la mi-janvier, après une mauvaise bronchite. Pendant sa courte hospitalisation, il a pu prendre congé de la famille avec beaucoup de sérénité, toute sa consciente et son habituel humour. Il est décédé le 25 janvier dans sa $88^{\text {e }}$ année.

Parmi ses nombreux assistants reconnaissants:

Peter Buess, Lucerne 